\title{
Improving Supply Chain Social Responsibility through Supplier \\ Development
}

\author{
Min Zhang* \\ Norwich Business School, \\ University of East Anglia, Norwich, UK, NR4 7TJ \\ E-Mail: m.zhang1@uea.ac.uk
}

Kulwant S. Pawar

Centre for Concurrent Enterprise, Nottingham University Business School

The University of Nottingham, Nottingham, UK, NG8 1BB

E-mail: Kulwant.Pawar@nottingham.ac.uk

\author{
Saurabh Bhardwaj \\ Nottingham University Business School, \\ The University of Nottingham, Nottingham, UK \\ E-mail: saurabhbhardwaj760@gmail.com
}

* Corresponding author 


\begin{abstract}
Corporate social responsibility (CSR) emphasizes that the entire supply chain of a company should protect natural environment and contribute to social well-being in a tangible way. This study aims to clarify the effects of supplier development practices on supply chain social responsibility. The investigation uses a qualitative case study approach and empirically explores how to develop supplier's CSR capabilities in a pharmaceutical supply chain. The results indicate that manufacturers can apply supplier development practices, including standard operating procedures (SOPs), audits, collaboration, and training, to develop supply chain social responsibility. SOPs and audits are indirect supplier development practices that are designed in response to institutional pressures, and collaboration and training are direct supplier development practices that provide resources for bridging supplier's CSR capability gaps. In addition, the indirect and direct supplier development practices positively influence each other and they are complementary in enhancing supply chain social responsibility. The findings improve extant knowledge on how to incorporate CSR into supply chain management processes.
\end{abstract}

Keywords Corporate social responsibility, supplier development, pharmaceutical supply chain 


\section{Introduction}

Facing various regulatory and community pressures, pharmaceutical companies have viewed corporate social responsibility (CSR) as a strategic issue (Smith 2008, Chaabane et al. 2011, Gimenez and Tachizawa 2012). Researchers argue that CSR in pharmaceutical industry is more than philanthropic activities (Leisinger 2005, Salton and Jones 2015) and multinational pharmaceutical companies have not been living up to their social responsibilities (Leisinger 2005, Rossetti et al. 2011). As pharmaceutical companies are boosting their efforts to source products and services from emerging economies and are working in partnerships with suppliers (Gupta et al. 2007, Smith 2008, Zhang et al. 2013), cases involving suppliers who operate irresponsibly have been widely reported and have centred on environmental and social issues (Smith 2008, Schneider et al. 2010). Hence, suppliers' capabilities and skills to deal with CSR challenges play critical roles in pharmaceutical companies' CSR performance (Foerstl et al. 2010, Schneider et al. 2010). However, there is limited empirical evidence on how to improve suppliers' CSR capabilities in the pharmaceutical industry (Smith 2008, Frederiksborg and Fort 2014).

Supplier development has been viewed as an important supply chain management method for a company to identify and select an adequate pool of suppliers to provide products and services needed by the company, and to improve their capabilities to meet the company's short- and/or long-term requirements (Krause and Ellram 1997, Krause et al. 1998). Studies have documented the benefits of supplier development on knowledge transfer and supply chain performance, including new product development, cost, quality, and delivery (Sanchez-Rodriguez et al. 2005, Krause et al. 2007, Modi and Mabert 2007, Rogers et al. 2007). Pharmaceutical companies are devoting more and more resources to supplier development programs (Foerstl et al. 
2010, Genovese et al. 2014). Such efforts enable companies to transfer knowledge and skills to suppliers and enhance their CSR and other performances (Humphreys et al. 2011, Ayuso et al. 2013).

Supplier development activities can be motivated by institutional pressures or suppliers' capability gaps (Rogers et al. 2007). In particular, the institutional theory argues that coercive, mimetic, and normative pressures affect companies' strategic decisions (DiMaggio and Powell 1983). Pharmaceutical companies develop codes of conduct and principles to manage supplier's activities to fulfil the requirements and expectations of external stakeholders, such as government agencies, collective industrial associations, regulators, non-government organizations (NGOs), and consumer groups, on supply chain's environmental (e.g. waste, material recycling, pollution, and product design) and social impacts (e.g. safety and health) (Linton et al. 2007). The resource-based view suggests that companies can use supply chain partner's resources, such as physical, human, intellectual, and financial resources, to develop skills and capabilities (Barney 1991). Pharmaceutical companies thus can improve supply chain social responsibility by investing in suppliers' facilities and equipment, training their personnel (Krause et al. 2007, Mahapatra et al. 2012), and managing suppliers in accordance with a code of sustainable business practices and a high standard of quality and compliance (Rossetti et al. 2011). However, the majority of current supplier development literature focuses on its effects on improving supplier's operational capabilities for designing and delivering innovative and cost-competitive components and services (e.g. Krause and Ellram 1997, Krause et al. 1998, Prahinski and Benton 2004, Modi and Mabert 2007, Humphreys et al. 2011), and does not address the realities and specificities of pharmaceutical supply chains (Rossetti et al. 2011, Frederiksborg and Fort 2014, Salton and Jones 2015). There is an acute need 
for empirically exploring how to manage supply chain social responsibility through supplier development in the pharmaceutical industry (Ashby et al. 2012, Garetti and Taisch 2012).

This study aims to explore how to improve supply chain social responsibility in the pharmaceutical industry through supplier development. More specifically, it focuses on the following two research questions. First, how can suppliers' CSR capabilities be developed in the pharmaceutical industry? Second, how do supplier development practices influence supply chain social responsibility?

\section{Theoretical background}

\subsection{Corporate social responsibility in pharmaceutical supply chains}

CSR can be defined as 'the firm's considerations of, and response to, issues beyond the narrow economic, technical, and legal requirements of the firm to accomplish social benefits along with the traditional economic gains which the firm seeks' (Davis 1973, 312). It is the voluntary actions designed to improve social conditions or the business behaviour that is not required by law but attempts to further some social good and extend beyond the explicit transactional interests of a company (Barnett 2007, Linton et al. 2007). Increasing public awareness together with new regulations are forcing companies to reconsider their operations with respect to social and environmental objectives (Chaabane et al. 2011). Environmental performance emphasizes the management of natural resources, and social performance is concerned with the management of social well-being (Davis 1973, Ashby et al. 2012). Good CSR performance can increase the trustworthiness of a company, strengthen its relationships with important stakeholders, and generate moral capital or goodwill (Barnett 2007, Salton and Jones 2015). 
Pharmaceutical companies operate in a globalized, highly regulated, and complex environment (Rossetti et al. 2011, Garetti and Taisch 2012, Brown and Vondracek 2013). External stakeholders emphasize that the pharmaceutical industry must adhere to strict product and process quality standards as well as implement sustainable and responsible operations and supply chain management practices (Veleva et al. 2003, Gupta et al. 2007). CSR thus has become an integral part of pharmaceutical companies' global supply chain strategies (Schneider et al. 2010, Parmigiani et al. 2011). Irresponsible supplier behaviour may cause adverse public image, reputational damages, and costly legal obligations for pharmaceutical companies (Linton et al. 2007, Smith 2008). Hence, when purchasing materials and components or outsourcing operations, pharmaceutical companies must incorporate CSR criteria into supplier management and use their power to generate positive social impact (Ashby et al. 2012). There is some empirical evidence on pharmaceutical companies' CSR initiatives. For example, Veleva et al. (2003) find that pharmaceutical companies predominantly measure the eco-efficiency and performance of CSR programs but the supply chain and life cycle issues are less emphasized. Leisinger (2005) argues that pharmaceutical companies ought to avoid questionable manufacturing practices and work legitimately beyond legal requirements, and can fulfil social responsibilities through corporate philanthropy, community and neighbourhood programs, volunteerism, and donations. Schneider et al. (2010) find that pharmaceutical companies provide information on application of management tools, energy and climate change efforts, expanded life cycle analysis, and efforts in traditional Safety, Health, and Environment (SHE) management in their voluntary sustainability reports. Frederiksborg and Fort (2014) suggest that CSR is more than philanthropic programs and pharmaceutical companies must build trust with external stakeholders. Salton and Jones (2015) reveal that the 
pharmaceutical industry's CSR activities require much improvement and the pharmaceutical industry needs to develop more relevant and specific CSR guidelines. Hence, fewer studies have addressed the best practices and processes pharmaceutical companies can apply to improve supply chain social responsibility (Marshall et al. 2015). There is a tangible need to develop a more focused understanding on how to develop suppliers' capabilities to meet pharmaceutical companies' environmental and social obligations (Oehmen et al. 2010, Chaabane et al. 2011, Ashby et al. 2012).

\subsection{Supplier development}

Supplier development can be defined as 'any set of activities undertaken by a buying firm to identify, measure and improve supplier performance and facilitate the continuous improvement of the overall value of goods and services supplied to the buying company's business unit' (Krause et al. 1998, 40). It represents a buying company's efforts that can enhance suppliers' capabilities and optimize supply chain processes (Krause and Ellram 1997). Supplier development enables a company to maintain capable supply bases, foster continuous improvement, and yield a long term cooperative supplier relationship, enhancing the company's competitive advantages (Krause and Ellram 1997, Modi and Mabert 2007, Humphreys et al. 2011).

Supplier development practices require different levels of involvement and investments (Sanchez-Rodriguez et al. 2005, Wagner 2011). In direct supplier development, buying companies commit relationship specific resources such as financial capital, human resources, know-how, technologies, and managerial capabilities (Krause 1999, Wagner 2010). It involves direct investments such as onsite consultation, training programs, temporary personnel transfer, and supplier development consortiums (Krause and Ellram 1997, Krause et al. 1998). Indirect supplier development is characterized by a buying company committing limited 
resources to suppliers. It generally uses information technology tools and market forces to monitor supplier performance (Krause 1999, Wagner 2010). Some common techniques used in indirect supplier development include supplier assessment, supplier recognition, communicating feedback, plant visits, performance measurement, and supplier auditing (Krause and Ellram 1997, Krause et al. 1998). Indirect supplier development is widely applied to monitor suppliers' operational performance whereas direct supplier development is considered better for enhancing suppliers' capabilities (Wagner 2010).

Improving supply chain social responsibility is a challenging job for small suppliers since conforming to required CSR standards can involve heavy costs in terms of time and expertise that are difficult for them to bear (Ayuso et al. 2013). Supplier development programs can provide support and resources to suppliers to ensure that their CSR capabilities are equal to or greater than a company's competitors' suppliers (Gimenez and Tachizawa 2012). Researchers argue that indirect supplier development practices enable buying companies to assess their supply bases and determine if suppliers are capable of meeting their CSR needs (Zhang et al. 2013). A structured evaluation and subsequent supplier selection allow a company to effectively manage a sustainable portfolio of suppliers (Foerstl et al. 2010). CSR requirements can be formulated either in invitation for proposal or purchasing specifications. Buying companies can also communicate the measurements and targets of CSR to suppliers, and monitor their performances and compliance with requirements through surveys or audits (Prahinski and Benton 2004, Ayuso et al. 2013). Although researchers have pointed out that direct supplier development is an effective tool in generating sustained CSR improvement (Locke 2012), studies exploring the relationships between indirect and direct supplier development practices and their joint effects on supply chain social 
responsibility have been scant (Genovese et al. 2014), and few if any researchers have investigated how pharmaceutical companies implement supplier development practices (Smith 2008, Schneider et al. 2010).

\subsection{Institutional theory and resource-based view}

The institutional theory argues that companies' practices and strategies are substantially influenced and shaped by the institutional settings in which they operate (DiMaggio and Powell 1983, Doh and Guay 2006). Institutional environments provide rule-like social expectations and norms about companies' operations and CSR performance (Campbell 2007, Matten and Moon 2008). DiMaggio and Powell (1983) argue that companies confront three types of institutional pressures. Coercive pressures refer to 'formal or informal pressures exerted on organizations by other organizations upon which they are dependent and by cultural expectations in the society within which organizations function' (DiMaggio and Powell 1983, 150). They originate from political influences from regulatory agencies and dominant partners in the institutional field (Bhakoo and Choi 2013). Mimetic pressures come from organizations' standard responses to uncertainty when they model themselves after other more progressive, legitimate, or successful organizations (DiMaggio and Powell 1983, Bhakoo and Choi 2013). Normative pressures are derived from professionalization (DiMaggio and Powell 1983). The institutional pressures drive companies to invest in supplier development to improve supply chain social responsibility (Rogers et al. 2007, Bhakoo and Choi 2013). Moreover, Meyer and Rowan (1977) argue that companies' actual practices may 'decouple' from their formal policies and procedures because they attempt to acquire legitimacy from institutional environments but are constrained by requisite resources and expertise to fulfil promises operationally. This indicates that incorporating CSR principles in contracts may not guarantee that suppli- 
ers will stick to the agreed codes of conduct if they are lack of resources or capabilities.

The resource-based view argues that resources and capabilities are heterogeneously distributed among companies and they can create competitive advantages if employed in distinctive ways (Barney 1991, Coates and McDermott 2002). A company's resources refer to the unique bundles of assets, capabilities, processes, and knowledge that are valuable, rare, imperfectly imitable, and nonsubstitutable (Barney 1991, McIvor 2009). Resources can be tangible (e.g. equipment and technologies) or intangible (e.g. knowledge and intellectual property). This view indicates that buying companies can be critical resource providers for suppliers to develop CSR capabilities (McIvor 2009, Salton and Jones 2015). Hence, if a company finds there are gaps between suppliers' capabilities and the company's CSR requirements, supplier development provides a way for the company to use their resources to bridge the gaps and improve supply chain social responsibility (Rogers et al. 2007, Smith 2008). Therefore, we develop the following research framework by combining the institutional theory and resource-based view, which is used to guide the empirical case study (Figure 1) (Miles and Huberman 1994). 


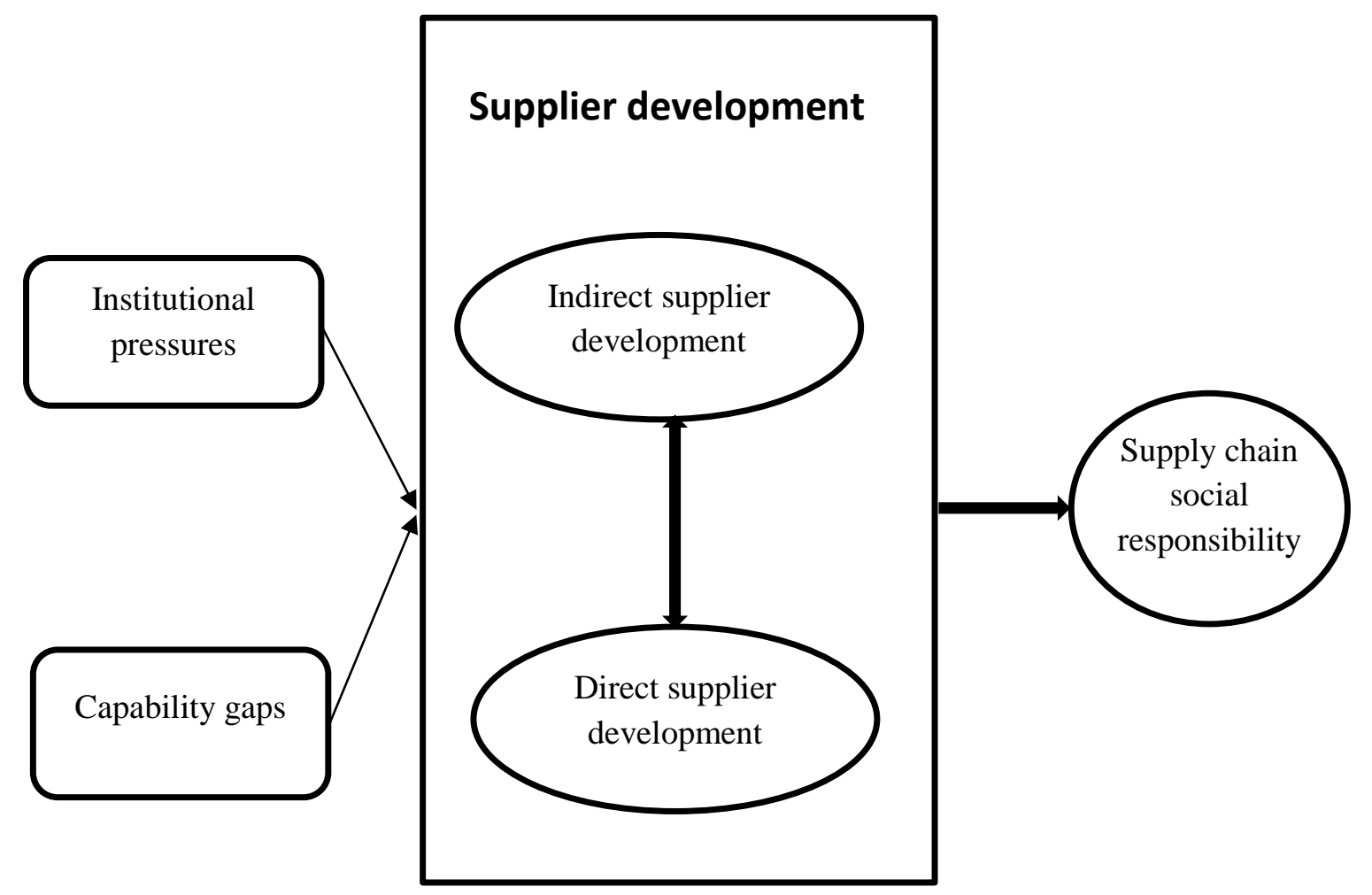

Figure 1. Research framework

\section{Research method}

We employed an in-depth qualitative case study approach in this study (Eisenhardt 1989, Ellram 1996, Childe 2011). This choice was motivated by the research objective (Voss et al. 2002). As relatively little is known about how to develop suppliers' CSR capabilities in the pharmaceutical industry (Veleva et al. 2003, Rossetti et al. 2011, Gimenez and Tachizawa 2012), this study aims to develop a detailed understanding on the effects of supplier development practices on supply chain social responsibility by observing actual practices (Voss et al. 2002, Mills et al. 2010). In-depth case study enables us to describe supplier development practices and investi- 
gate the linkages between supplier development and supply chain social responsibility in real-world pharmaceutical supply chains (Gibbert et al. 2008, Childe 2011).

\subsection{Case selection}

We selected a multinational pharmaceutical company (MPC)'s clinical supply chain (CSC), or the pharmaceutical research and development (R\&D) supply chain as it is commonly known, to conduct this case study for two reasons. First, we organized a focus group workshop in 2011 (Rossetti et al. 2011). A group of 25 senior executives from the pharmaceutical industry discussed how to build a responsible pharmaceutical supply chain. During the discussion, the participants pointed out that CSC provides a highly dynamic and complex context to study CSR in the pharmaceutical industry. One senior director commented, 'The CSC is a key contributor to $R \& D$ productivity at our organisation with huge amounts of money at stake; benefits as well as losses can be significant.' An executive vice-president commented, 'CSC is critical to patient safety, product quality, and our reputation. We are outsourcing more of our manufacturing and working with suppliers in more countries worldwide. We need to do this in a considered way, with the right safeguards in place, and be transparent about our approach. Reducing costs is not acceptable if it means compromising on quality or our values.' Moreover, suppliers must ensure that clinical trial supplies and study drugs reach investigation sites in a timely, controlled, and cost effective manner (Brown and Vondracek 2013). Therefore, the implementation and integration of CSR criteria with existing CSC can be time and resource intensive and inherently challenging.

Second, we reviewed the top 12 pharmaceutical companies' sustainable development reports ranked by annual revenue (Veleva et al. 2003, Schneider et al. 2010). MPC has shown sophisticated and advanced global supplier development 
practices and excellent CSR performance. For example, MPC partners with suppliers that embrace social responsibility, engages with suppliers regularly (e.g. business conferences, workshops, forums, executive programmes, onsite quality audits and reviews, and targeted training sessions), and works together with suppliers on cost reduction and financial stability. MPC participates in the Global Reporting Initiative project and is one of the few companies that report level 4 supply chain and product life cycle SHE indicators to public (Veleva et al. 2003). MPC has also been ranked top of the health sector for its standards for suppliers (100\% rating) in Dow Jones Sustainability Index. Hence, the research team believed MPC's CSC is a representative best-in-class case to investigate supplier development and supply chain social responsibility in the pharmaceutical industry (Voss et al. 2002, Yin 2009).

\subsection{Data collection}

The data sources for this study included face-to-face interviews, information from the Internet, personal observations, and company documents. The multiple sources of evidence strengthened the analysis by allowing triangulation on important issues to cross-verify insights and findings (Yin 2009).

The interviews were guided by a semi-structured protocol (Appendix 1), which was initially developed based on the research questions, research framework, and the focus group workshop discussion. In total, the fieldwork for this study spanned a period of four months in 2012. A member of the research team was based in MPC's office, and was able to aggregate relevant company data and arrange the interviews. Each interview lasted approximately 1 to 2 hours. Supply chain managers, study management teams, sourcing managers, and quality assurance (QA) teams as well as the points of contact within a supplier were interviewed (Appendix 2). Supplier site visits across different locations were organized to facilitate the supplier interviews. The re- 
search team members conducted debriefing meetings both before and after each interview to share information and experiences and to review the logic and contents of the interviews (Miles and Huberman 1994). We also developed a case database, which includes interview transcripts (on average, 30 pages for each interview), case study notes (i.e. 40 pages), information from Internet (i.e. 40 pages), and MPC's internal documents (i.e. 100 pages). The draft report was reviewed by two researchers and seven interviewees for the logic and contents (Ellram 1996). The measures used for ensuring validity and reliability throughout the case study are summarized in Table 1

(Gibbert et al. 2008, Yin 2009).

Table 1. Validity and reliability tests

\begin{tabular}{|l|l|}
\hline Validity and reliability criteria & Case study tactics \\
\hline Construct validity & 1. Using multiple sources of evidence to \\
triangulate data (e.g. face-to-face interviews with \\
both MPC and its supplier, information from the \\
Internet, personal observations, and company \\
documents) (section 3.2). \\
2. Establishing chain of evidence (e.g. the \\
interview details, indication of data collection \\
circumstances, and clarification of data analysis \\
approach) (appendix 2, section 3.2, and section \\
$\begin{array}{ll}\text { 4.2). } \\
\text { 3. The draft report was reviewed by two re- } \\
\text { searchers and seven interviewees for the logic } \\
\text { and contents (section 3.2). }\end{array}$ \\
\hline $\begin{array}{l}\text { I. The case study was guided by a clear research } \\
\text { framework (figure 1). } \\
\text { 2. Using pattern matching logic to compare the } \\
\text { empirically identified patterns with the predicated } \\
\text { patterns (section 4.2). }\end{array}$ \\
\hline External validity & $\begin{array}{l}\text { 1. Rationale for the case selection (section 3.1). } \\
\text { 2. Details of the case study context (section 4.1 } \\
\text { and appendix 3). } \\
\text { 3. The case study was guided by the institutional } \\
\text { theory and resource-based view (section 2.3). }\end{array}$ \\
\hline Reliability & $\begin{array}{l}\text { 1. The interviews were guided by a semi- } \\
\text { structured protocol (appendix 1). } \\
2 . \text { We developed a case study database, which } \\
\text { includes interview transcripts, case study notes, } \\
\text { information from Internet, and MPC's internal } \\
\text { documents (section 3.2). }\end{array}$ \\
\hline
\end{tabular}




\section{Analysis and discussion}

\subsection{Case description}

MPC employs over 60,000 people and has established product lines in over 100 countries. With headquarters in Europe, the U.S.A., Europe, China, Russia, South America, Japan, and South Asia are MPC's strategic markets and each of these locations also serves as critical R\&D hubs connected by a global CSC. In recent years, MPC has increased the amount of outsourcing across several business functions and has been seen to develop close-knit and long-term strategic relations with its suppliers with the intent to drive innovation and efficiency in pharmaceutical $R \& D$, production, and distribution. The company has rationalised its supply base considerably and has been actively improving its CSC's social responsibility.

The clinical study management group within MPC is responsible for managing and delivering clinical trials in a safe, timely, and cost effective manner. All potential new drugs must undergo Phase I - III clinical trials before they are submitted to regulatory authorities for gaining market approval. After a medicine is launched, MPC must then run Phase IV trials to get more information on a specific aspect of the product's performance. CSC is concerned with delivering investigational drugs from the point of manufacturing to the point of use (i.e. investigation sites) (Appendix 3). MPC must rapidly set up new clinical studies every year as well as abandon or close inconclusive studies. Currently, it has 92 products in clinical development and a total of 126 clinical products being tested simultaneously. A total of approximately 50 studies were abandoned in 2010. Studies tend to last anywhere between 2-8 years, and are generally carried out across multiple sites requiring logistics and other ancillary service support for the entire duration. MPC increasingly relies on a strategic CSC to ensure the sustainability and responsibility of clinical studies. 


\subsection{Case analysis}

The data collected from the fieldwork was presented using a standardised template, ensuring the data was analysed in a consistent, logical, and coherent manner (Miles and Huberman 1994, Yin 2009). We used the pattern matching logic in the data analysis (Voss et al. 2002, Gibbert et al. 2008). In particular, the empirically identified supplier development practices were compared with the predicated ones, which were developed based on the institutional theory and resource-based view. The theory-driven approach enables us to analytically generalize the empirical observations to theoretical propositions (Yin 2009, Mills et al. 2010).

We find that MPC goes well beyond transactional relationships in CSC. MPC has become a network integrator due to the increasing degree of outsourcing over the last few years. The managers believe that being a responsible pharmaceutical company means upholding ethical standards throughout the entire CSC including sourcing, packaging and labelling, manufacturing, returning and destructing, and total transportation management. It has worked hard to raise awareness on issues like environmental protection, waste management, labour policies, and patient well-being, which not only require a significant investment but also time to implement and cascade into supplier's processes and other associated networks. MPC desires to become a leader in the field of CSR and to take the company a step beyond its environmental and social obligations stipulated by CSR directives and guidelines. Indeed, this strategic initiative is also intended to avoid any potential incidents involving suppliers. Suppliers are required to comply with international, national, and local laws and MPC's principles, and to take account of any regulatory guidance or advice that applies to business activities. MPC deliberately chooses to conduct business with CSR compliant partners, even though it entails a slightly lengthier 
procurement process and a higher cost. MPC's managers explain that those suppliers will decrease costs and risks in CSR, resulting in financial gains in the long term.

MPC recognises the need to incorporate institutional pressures from various stakeholders and to invest resources in supplier's capability improvement. There is a strong belief amongst MPC's senior managers that advanced and transparent supplier development initiatives will make good business and economic sense and also foster collaborative R\&D. In the long run, they will contribute to MPC's desire to become an even more prominent company with a positive corporate reputation and image in the industry. To build a sustainable and responsible CSC, MPC has adopted and implemented several supplier development practices, including process standardization, auditing, supply chain collaboration, and training/education of supplier personnel.

\subsubsection{Standard operating procedures}

MPC has launched standard operating procedures (SOPs) to manage CSC's global capability, performance, perceived risk levels, and SHE standards. These SOPs, which are based on the Pharmaceutical Supply Chain Initiative's (PSCI) (a consortium of established multinational pharmaceutical companies) principles and guidance and MPC's own CSR strategy, are defined at both strategic and operational levels to provide instructions on supply chain management and CSR standards. MPC formalises the CSR requirements with the aid of clauses included in the specifications and service level agreements, which outline the responsibilities of suppliers and the required level of CSR. There are also clauses to protect MPC from CSR failures. Outstanding issues that have arisen out of due diligence and improvement plans are also included in contracts. 
SOPs describe the purpose, scope, definitions, procedure, responsibilities, and training guidelines for efficient management of suppliers. They are used to maintain consistency in processes and ensure that protocols are being followed. They ensure that suppliers comply with worldwide quality and regulatory requirements as well as MPC's policies in CSR. A manager commented, 'Being a responsible business includes making sure that we work only with suppliers who have ethical standards that are consistent with our own'. Over the last two years, MPC has reviewed and republished SOPs to provide clear directions as to how to integrate responsibility into business decisions. SOPs can be classified into three tiers (Table 2). In general, Tier 1 SOPs tend to be more strategic and have a broad focus while Tier 2 and Tier 3 SOPs deal with specifics and operational details, for instance, the CSR audit of a particular type of facility or the reporting/follow-up protocol to be used.

Table 2. Standard operating procedures

\begin{tabular}{|c|l|}
\hline Tier 1 & $\begin{array}{l}\text { Broad strategic guidelines, roles, and responsibilities, for } \\
\text { example, guidelines for conducting audits of internal and } \\
\text { external facilities. }\end{array}$ \\
\hline Tier 2 & $\begin{array}{l}\text { Focused guidelines and checklists based on the tasks, for } \\
\text { example, guidelines for audits of a distribution site with respect } \\
\text { to warehouse infrastructure, storage areas, temperature } \\
\text { monitoring systems, labelling and packing areas, processes, QA } \\
\text { routines, labelling systems, and SHE compliance. }\end{array}$ \\
\hline Tier 3 & $\begin{array}{l}\text { Recommended reporting procedures or action plans for a } \\
\text { particular product/scenario, for example, SOPs for error } \\
\text { reporting, feedback, and follow-up for escalations at a } \\
\text { distribution site. }\end{array}$ \\
\hline
\end{tabular}

Supplier management is carried out in four phases based on the SOPs: selection, establishment, maintenance, and termination. SOPs provide a clear checklist of assessments to be conducted. A new supplier selection process is a cross-functional exercise where members from $\mathrm{R} \& \mathrm{D}$, sourcing, QA, and operations make an evaluation of the suppliers' CSR performance. The selection process is often based on a detailed due diligence assessment on suppliers' capabilities and SHE compliance, 
and a comparative supplier benchmarking exercise. During the establishment phase, the service and QA agreements are drafted and agreed upon. It also involves developing a clear idea of the roles and responsibilities of the various personnel involved in the service agreement and later the details of the technical/regulatory documents transfer between MPC and a supplier.

The maintenance phase is about ensuring that a steady supply of products and services is maintained by the supplier. While there are generally applicable guidelines, some amount of flexibility is expected, depending on the type of material/service supplied, in the local procedures for maintaining seamless supplier delivery. Termination is the phase where MPC would transition out of a supply agreement with a supplier and do so in an organized and thorough manner, with the least risk or liability going forward. The SOPs thus ensure compliance with CSR guidelines and regulatory requirements and inclusion of procedures considered to be responsible and ethical during sourcing.

\subsubsection{Audit}

The goals of audits are to identify potential CSR risks in the system and to manage them proactively rather than to transfer the risks in CSC. Audits are designed to ensure compliance with local and international quality and CSR standards, and MPC's codes of conduct. They are also essential tools to assess performance and identify areas for corrective actions and improvement. An elaborate audit function ensures that the QA mandate is being met and that MPC will not encounter financial liability because of supplier's non-compliance or SHE incidents. Audits help to monitor works in disparate supplier locations and are critical for understanding the areas in which a supplier is doing well and those where further improvement is needed. They also provide useful opportunities for suppliers to discuss any practical 
difficulties they face in meeting MPC's global commitment on social responsibility at a local level.

MPC uses a combination of planned and unannounced audits. Third party auditors are used to increase oversight of suppliers and to provide an independent perspective. The audit programme considers suppliers' internal (e.g. systems, procedures and data) and external/outsourced items (e.g. obtained via contractors or vendors) under the span of their responsibilities. Different kinds of audits are carried out to identify a range of issues with regard to quality, materials, production processes, facilities and equipment, laboratory standards and practices, and SHE issues (Table 3).

Table 3. Audits

\begin{tabular}{|l|l|}
\hline \multicolumn{1}{|c|}{ Audits } & \multicolumn{1}{c|}{ Triggers/Criteria/ Purpose } \\
\hline Qualification Audits & $\begin{array}{l}\text { To assess suppliers' compliance with international } \\
\text { and MPC's CSR standards. Qualification audits also } \\
\text { include new product introduction and due diligence } \\
\text { audits. }\end{array}$ \\
\hline $\begin{array}{l}\text { Routine Good Manufacturing } \\
\text { Practice Audits }\end{array}$ & $\begin{array}{l}\text { To ensure suppliers' facilities and processes are } \\
\text { compliant with international regulations for } \\
\text { sustainability, quality, and safety. }\end{array}$ \\
\hline $\begin{array}{l}\text { For Cause Audits } \\
\text { Risk Based Audits and } \\
\text { Reviews) }\end{array}$ & $\begin{array}{l}\text { Risk based audits are carried out when there is a } \\
\text { reported incident, for instance, evidence of poor drug } \\
\text { storage or delivery practices. }\end{array}$ \\
\hline Follow-up Audits & $\begin{array}{l}\text { To ensure that the feedback from previous audits has } \\
\text { been implemented, and critical and non-critical } \\
\text { observations are being handled as per the prescribed } \\
\text { course of action. }\end{array}$ \\
\hline $\begin{array}{l}\text { Mock Pre-Approval } \\
\text { Inspection (PAI) }\end{array}$ & $\begin{array}{l}\text { A mock PAI is performed as a preparation for hosting } \\
\text { an external authority inspection related to a recent } \\
\text { regulatory filing/query. }\end{array}$ \\
\hline
\end{tabular}

The audit process is organised in three stages: (1) audit initiation and planning, in which the tasks, roles, and responsibilities of auditors are determined and ascertained; (2) audit execution, which is based on the SOPs for audit of a particular grade or with respect to a particular audit area like facilities, processes, and SHE; and (3) audit documentation and closure, which include audit notification/disclosure, reporting, follow-up, and audit frequency and control. The auditor(s) usually interviews relevant 
personnel concerning organisational processes, people skill levels, facilities, documentation, and non-routine operations to evaluate suppliers' CSR performance. This process is coupled with a tour of facilities at the sites and a review of documentation. The frequency of such audits will be based on the observations noted and the improvement plan and timeline applicable.

\subsubsection{Collaboration}

Supplier development is also supported by strategic investments in supply chain collaboration. MPC's senior manager commented, 'We disclose all the possible risks to our suppliers upfront and help them tackle those issues, as opposed to a completely hands off approach. We are working together more closely than ever before and are looking to secure time, cost-effective and safe supply of our products globally.' Strategic collaboration between MPC and suppliers takes the form of long-term partnership, and practices such as co-location, co-development, and service customisation are implemented. For instance, based on feedback from suppliers about the preferred location of a supply depot, MPC plans to set up a fully functioning packing, storage, and distribution facility, which will then be able to support a new direct to site distribution model and improve suppliers' CSR capabilities. In particular, this facility will save close to $30 \%$ distribution costs, reduce the carbon footprint as less regional depots are needed, reduce comparator wastage, and enhance trial and patient safety. Participation of suppliers' managers on MPC's steering committee for the new distribution centre is a noteworthy aspect of supply chain collaboration. The steering committee oversees layout, processes, training, quality assessments, and compliance issues with regard to the new distribution hub.

A recent initiative to launch a brand new product portfolio in China represents an advanced stage of collaboration. MPC plans to take a portfolio of 20 generic 
molecules to the market with a market value of close to $\$ 1$ billion annually. After a detailed assessment of the potential partners for this venture, the company selected 2 suppliers to co-develop 2 unique generic molecules. Each supplier will be in charge of 1 molecule and entirely responsible for the R\&D, registration and approval, and technical transfer for their allocated molecule. Suppliers act as the internal R\&D wing of MPC and then transfer the knowledge and intellectual property to MPC's manufacturing facility through a technical transfer for mass production. MPC supports the project with a task force of 50 personnel during the initial stage. They are responsible for portfolio and project planning, sales forecasting, technical and knowledge transfer, quality control, and SHE compliance. MPC also helps suppliers design operational processes that fulfil MPC's CSR criteria. In addition, MPC provides customized Clinical Trial Management Software, which is developed based on its experiences and expertise in managing clinical trials and social responsibility, to suppliers.

\subsubsection{Training}

Another key aspect of supplier development at MPC is supplier training and it plays an important role in engaging suppliers, building trust, and fostering innovation, thus improving suppliers' CSR capabilities. Training is initiated by setting strategic CSR objectives based on historical performance data and survey feedback from key stakeholders at MPC. A Cross Functional Team (CFT) constituting QA, sourcing, and operations management personnel is formed to identify areas for improvement based on the strategic objectives laid out. MPC organises training and CSR knowledge transfer in suppliers' sites, drives buy-in from local staff, and prepares for the changes proposed by the CFT, such as improvement on their handling of study drugs at regional depots, tracking and tracing protocols, delivery timelines, and import and 
customs bottlenecks. MPC also rewards noteworthy improvement in CSR through a supply excellence award at an annual event.

CFT works with suppliers to help them improve capabilities and skills, and achieve the CSR goals set out in their improvement plans. Moreover, MPC requires Tier 1 suppliers to transfer the learned CSR methods and processes to their suppliers. In this way, the results of training get handed down to Tier 2 and 3 suppliers in CSC and this helps to maintain an integrated chain of control. Hence, key performance indicators for third party service providers are also streamlined and improved. To sustain these improvements, open communication channels are set-up, with personnel engaging on a monthly basis.

\subsection{Research propositions}

The analysis indicates that MPC's supplier development programs include SOPs and audits, which are indirect supplier develop practices reflecting institutional pressures from stakeholders, as well as collaboration and training, which are direct supplier development practices designed based on suppliers' capability gaps (Rogers et al. 2007, Wagner 2010, Locke 2012). SOPs not only provide a detailed guidance on product, service, and function level tasks, but also help suppliers develop a clear understanding of CSR criteria and techniques (Krause and Ellram 1997, Humphreys et al. 2011). Tier 1 SOPs are developed based on the PSCI principles and codes of conduct. They reflect external stakeholders' expectations on MPC's commitment to SHE performance and related management systems, which represent coercive pressures (Oehmen et al. 2010, Bhakoo and Choi 2013). Tier 2 and Tier 3 SOPs follow PSCI's implementation guidance documents, which are developed by a group of leading pharmaceutical companies. Hence, they represent both mimetic and normative pressures (Bhakoo and Choi 2013). Therefore, MPC launches the SOPs to communicate 
its CSR obligations to suppliers and formalise suppliers' everyday operations. Moreover, frequent audits and quality reviews ensure that CSR standards are maintained throughout CSC. By auditing, MPC can gather information about suppliers' performance on social and environmental practices, which can be used to guide supply chain social responsibility initiatives (Wild and Zhou 2011). Alongside compliance management, audits can evaluate whether suppliers are well-equipped and organised to approval inspections and benchmarking exercises. Such information can be used to evaluate the decupling of supplier's everyday operations from SOPs (Meyer and Rowan 1977). Hence, the indirect supplier development practices are the results of institutional pressures and can provide information and knowledge that can improve supply chain social responsibility.

The analysis also shows that MPC uses collaboration and training as strategic tools to provide physical, human, and organizational resources to suppliers and bridge suppliers' CSR capability gaps, enabling MPC to gain competitive advantages in supply chain social responsibility (Krause et al. 1998). MPC's direct supplier development programs can improve suppliers' facilities, employees' skills, and systems and processes. MPC is also responsible for coordinating supply chain processes and managing third party vendors of products and services. Supply chain collaboration is not only driven by securing greater profit margins, but also by the decision to improve supply chain social responsibility (Ulbrich et al. 2011). With the help of sophisticated analytical and tracking tools and top management commitment, MPC has designed mutually beneficial training programs with suppliers, which integrate risk management and encourage suppliers to engage in continuous improvement initiatives on CSR (Krause and Ellram 1997). Collaborative efforts also lead to better information sharing and more relational specific investments, enhancing suppliers' CSR capabili- 
ties (Giannakis 2008). Suppliers can learn from collaboration experiences which allow them to adapt their behaviour patterns to promote CSR (Ulbrich et al. 2011). Training also enables MPC to transfer skills and experiences on CSR to suppliers (Pawar and Rogers 2014), which improves supply chain social responsibility (Giannakis 2008). In addition, training enables suppliers to integrate MPC's investments with their resources base in unique ways, which can improve social and environmental performance in CSC (McIvor 2009). Hence, the direct supplier development practices can improve suppliers' CSR capabilities which are positively associated with supply chain social responsibility. Therefore, we propose that in the pharmaceutical industry:

P1: SOPs and audits are indirect supplier development practices designed according to institutional pressures and they can improve supply chain social responsibility.

P2: Collaboration and training are direct supplier development practices designed according to suppliers' capability gaps and they can improve supply chain social responsibility.

The analysis indicates that indirect and direct supplier development practices positively influence each other and are complementary in improving supply chain social responsibility. Besides requirements and advices, detailed guidelines regarding collaboration and training standards and processes are comprehensively outlined in SOPs. SOPs also clarify MPC and suppliers' roles and responsibilities to ensure consistent application of supplier development practices on a global scale. Hence, SOPs facilitate the implementation of direct supplier development practices. In addition, collaboration and training contribute to supply chain social responsibility by providing suppliers resources. SOPs allow MPC to keep past successful experiences 
as well as learn best practices from competitors, enhancing the effectiveness of direct supplier development. Audits support collaboration and training by providing information regarding to the gaps in CSR performance and the priorities for improvement (Zhang et al. 2013). In particular, audit observations are classified into critical, major, or minor categories. For critical observations, immediate corrective actions are required. All critical observations must be reported to senior management via a formal compliance issue reporting process and a functional continuous assurance process. For major and minor observations, corrective actions are required within the span of a month, quite often even sooner if the risk of CSR is high. According to auditing results, MPC and suppliers can come to a consensus regarding collaboration and training objectives and gaps in CSR capabilities. Hence, MPC can devise customized collaboration and training programs that highlight suppliers' specific CSR capability gaps, enhancing the effectiveness of MPC's resource investments. Therefore, resource investment decisions in supplier development are guided by SOPs and audits. Indirect supplier development practices not only build a foundation for direct supplier development practices but also enhance their effects on supply chain social responsibility (Barney 1991).

Direct supplier development practices also positively influence indirect supplier development efforts and amplify their effects on supply chain social responsibility. Collaboration and training are on-going processes that address changing CSR trends and emerging CSR threats, enabling suppliers to meet required CSR criteria (Gimenez and Tachizawa 2012). As a result, MPC has a greater involvement with, and a better understanding about suppliers' capabilities and operations (Sanchez-Rodriguez et al. 2005). Audits and SOPs should be able to keep up with changes in suppliers' capabilities and reflect new situations. The knowledge obtained through collaboration 
and training can provide inputs into the SOP designs and be incorporated into clauses appertaining to ethical, legal, and environmental practices (Oehmen et al. 2010). As commented by a supplier, 'The QA procedures have been co-developed by us to ensure better compliance (with the company standards) as well as reliability'. Moreover, collaboration and training enable MPC to get feedback from suppliers with precision and care, which allows MPC to customize audits. SOPs and audits contribute to supply chain social responsibility by providing guidelines and procedures, and information about suppliers' CSR capabilities, respectively. The value of SOPs is realized by the collaboration and training practices because they determine the transformation from SOPs to supply chain social responsibility. The effectiveness of SOPs can be attenuated if the collaboration and training programs are not well designed or implemented. Similarly, the value of audits on supply chain social responsibility can be amplified if a pharmaceutical company can assimilate the audit results and apply such knowledge into direct supplier development practices (Pawar and Rogers 2014). Hence, indirect and direct supplier development jointly influence supply chain social responsibility. Therefore, we propose that in the pharmaceutical industry:

P3: Indirect and direct supplier development practices positively affect each other.

P4: Indirect and direct supplier development practices are complementary in improving supply chain social responsibility.

\section{Conclusions and implications}

We have highlighted how MPC has taken organised and consistent steps to implement supplier development programs in its CSC. The findings reveal that MPC 
applies both indirect (i.e. SOPs and audits) and direct (i.e. collaboration and training) supplier development practices to manage supply chain social responsibility. Indirect and direct supplier development practices are developed according to institutional pressures and supplier's capability gaps, respectively. Moreover, we find that the indirect and direct development practices positively influence each other. They enhance supply chain social responsibility both individually and interactively.

\subsection{Theoretical and practical implications}

This study contributes to literature in two ways. First, the extant literature mainly emphasizes 'what is to be done' rather than how to improve CSR in the pharmaceutical industry and application-oriented research is rare (Leisinger 2005, Frederiksborg and Fort 2014). Researchers also give less attention to the social dimension of CSR in relation to supply chains (Linton et al. 2007, Ashby et al. 2012). In addition, the majority of existing empirical studies take an internal perspective and focus on pharmaceutical companies' overall CSR strategies and performance (Veleva et al. 2003, Smith 2008, Schneider et al. 2010, Salton and Jones 2015). The findings contribute to the CSR literature by adopting a supply chain perspective and providing in-depth empirical evidence on the supplier development practices a multinational pharmaceutical company applied for improving CSR. This study focuses on both environmental and social dimensions of CSR and the results thus provide integrated understandings of how to develop supply chain social responsibility in the pharmaceutical industry. Pharmaceutical companies have been recognized as leaders in sustainability (Frederiksborg and Fort 2014). Examining the best practices in this sector can shed light on the leading edge CSR practices. By linking CSR with operations and supply chain management, this study also enhances current understandings on the micro foundations of CSR. 
Second, this study contributes to the supply chain management literature by clarifying the complex relationships between supplier development practices and supply chain social responsibility. The findings are consistent with existing empirical results on the positive impact of supplier development practices on supplier capabilities and supply chain performance (Krause et al. 1998, Sanchez-Rodriguez et al. 2005, Krause et al. 2007, Wagner 2010, Humphreys et al. 2011). This study enhances current understandings on the consequences of supplier development by providing empirical evidence that supplier development practices are effective tools for improving supply chain social responsibility. In addition, by combining the institutional theory and resource-based view, we argue that indirect and direct supplier development practices are driven by institutional forces and suppliers' capability gaps respectively. Such findings provide insights into the driving forces of indirect and direct supplier development practices (Rogers et al. 2007), enabling pharmaceutical companies to customize their supplier development practices in response to changes in business and institutional environments. The findings also reveal that indirect and direct supplier development practices positively influence each other and are complementary in enhancing supply chain social responsibility. This study thus further clarifies the interrelationships between the two types of supplier development (Wagner 2010) and extends existing knowledge on the impact of supply chain management on CSR performance in the pharmaceutical industry (Gupta et al. 2007, Foerstl et al. 2010, Brown and Vondracek 2013). The supplier development practices identified in this study also build a foundation for researchers to develop measures for supplier development in the pharmaceutical industry, which can be used to investigate the effects of supplier development using large scale surveys. 
This study also provides guidelines for managers in the pharmaceutical and other manufacturing industries to devise and apply supplier development practices to improve supply chain social responsibility and effectively manage and mobilise knowledge about CSR in supply chains. In particular, we suggest managers develop SOPs based on law, regulations, industry principles, and a company's SHE standards to provide strategic guidelines and operational details for audits, collaboration, and training. A company's SOPs should also reflect the expectations of external stakeholders, including government agencies, NGOs, and consumers. Moreover, companies should collaborate with competitors to develop industry standards. Supplier audits should be applied to gather information about suppliers' CSR performance and feedback from collaboration and training. Managers should develop a portfolio of audits (e.g. qualification, routine good manufacturing practice, for cause, and follow-up audits) and the audit processes should be carefully designed. Audits should also reflect the institutional pressures from external stakeholders and we suggest managers use third party auditors and a combination of planned and unannounced audits. In addition, we suggest managers invest in both tangible and intangible resources to collaborate with suppliers and provide training to suppliers. Collaboration and training should be designed based on SOPs and audit findings, and guided by suppliers' CSR capability gaps. For example, a manufacturer could colocate and co-develop new products with suppliers. Customized training programs should also be implemented to enable suppliers to develop a better understanding on a buyer's CSR criteria and standards, and learn advanced skills on how to improve CSR performance. Moreover, managers should be aware that the four supplier development practices are interrelated. SOPs and audits provide guidelines and information for a manufacturer to customize collaboration and training. Collaboration and training can 
improve suppliers' capabilities and hence suppliers can provide suggestions to improve SOPs. The costs and lead-times for audits can also be reduced. Hence, we suggest managers implement indirect and direct supplier development practices simultaneously to capture the complementary effects and fully reap their benefits on supply chain social responsibility improvement.

\subsection{Limitations and future research directions}

While this study makes significant theoretical and practical contributions, it has limitations that open up avenues for future studies. First, this study uses an in-depth case study approach and the data is collected from one multinational pharmaceutical company and its supplier. In addition, the analysis is mainly based on qualitative data. Large scale surveys could be conducted to quantify the key constructs, such as indirect and direct supplier development and supply chain social responsibility, and empirically test and validate the propositions. Second, social capital in supplier-buyer relationships plays a critical role in supply chain management. Investigating the effects of social capital on the relationships between supplier development and supply chain social responsibility could be an interesting topic. Third, researchers argue that supply chain management practices, such as postponement and integration, also influence supplier development (Krause et al. 2007, Humphreys et al. 2011). Future studies could link supplier development with other supply chain management practices and investigate their joint effects on supply chain social responsibility.

\section{References}

Ashby, A., Leat, M. \& Hudson-Smith, M., 2012. Making connections: A review of supply chain management and sustainability literature. Supply Chain Management: An International Journal, 17 (5), 497-516. 
Ayuso, S., Roca, M. \& Colome, R., 2013. SMEs as "transmitters" of CSR requirements in the supply chain. Supply Chain Management: An International Journal, 18 (5), 497-508.

Barnett, M.L., 2007. Stakeholder influence capacity and the varibility of finanical returns to corporate social responsibility. Academy of Management Review, 32 (3), 794-816.

Barney, J., 1991. Firm resources and sustained competitive advantage. Journal of Management, 17 (1), 99-120.

Bhakoo, V. \& Choi, T., 2013. The iron cage exposed: Institutional pressures and heterogeneity across the healthcare supply chain. Joournal of Operations Management 31 (6), 432-449.

Brown, S. \& Vondracek, P., 2013. Implementing time-based manufacturing practices in pharmaceutical preparation manufacturers. Production Planning \& Control, $24(1), 28-46$.

Campbell, J.L., 2007. Why would corporations behave in socially responsible ways? An institutional theory of corporate social responsibility. Academy of Management Review, 32 (3), 946-967.

Chaabane, A., Ramudhin, A. \& Paquet, M., 2011. Designing supply chains with sustainability considerations. Production Planning \& Control, 22 (8), 727-741. Childe, S.J., 2011. Case studies in operations management. Production Planning \& Control, 22 (2), 107-107.

Coates, T.T. \& Mcdermott, C.M., 2002. An exploratory analysis of new competencies: A resource based view perspective. Journal of Operations Management, 20 (5), 435-450. 
Davis, K., 1973. The case for and against business assumption of social responsibilities Academy of Management Journal, 16 (2), 312-322.

Dimaggio, P.J. \& Powell, W.W., 1983. The iron cage revisited: Institutional isomorphism and collective rationality in organizational fields. American Sociological Review, 48 (2), 147-160.

Doh, J.P. \& Guay, T.R., 2006. Corporate social responsibility, public policy, and NGO activism in Europe and the United States: An intitutional-stakeholder perspective. Journal of Management Studies, 43 (1), 47-73.

Eisenhardt, K.M., 1989. Building theories from case research. Academy of Management Review, 14 (4), 532-550.

Ellram, L.M., 1996. The use of the case study method in logistics research. Journal of Business Logistics, 17 (2), 93-138.

Foerstl, K., Reuter, C., Hartmann, E. \& Blome, C., 2010. Managing supplier sustainability risks in a dynamically changing environment—sustainable supplier management in the chemical industry. Journal of Purchasing \& Supply Management, 16 (2), 118-130.

Frederiksborg, A. \& Fort, T.L., 2014. The paradox of pharmaceutical CSR: The sincerity nexus. Business Horizons, 57 (2), 151-160.

Garetti, M. \& Taisch, M., 2012. Sustainable manufacturing: Trends and research challenges. Production Planning \& Control, 23 (2/3), 83-104.

Genovese, A., Koh, S.C.L., Kumar, N. \& Tripathi, P.K., 2014. Exploring the challenges in implementing supplier environmental performance measurement models: A case study. Production Planning \& Control, 25 (13/14), 1198-1211. 
Giannakis, M., 2008. Facilitating learning and knowledge transfer through supplier development. Supply Chain Management: An International Journal, 13 (1), $62-72$.

Gibbert, M., Ruigrok, W. \& Wicki, B., 2008. What passes as a rigorous case study? Strategic Management Journal, 29 (13), 1465-1474.

Gimenez, C. \& Tachizawa, E.M., 2012. Extending sustainability to suppliers: A systematic literature review. Supply Chain Management: An International Journal, 17 (5), 531-543.

Gupta, A., Pawar, K.S. \& Smart, P., 2007. New product development in the pharmaceutical and telecommunication industries: A comparative study. International Journal of Production Economics, 106 (1), 41-60.

Humphreys, P., Cadden, T., Li, L.W. \& Mchugh, M., 2011. An investigation into supplier development activities and their influence on performance in the Chinese electronics industry. Production Planning \& Control, 22 (2), 137-156.

Krause, D.R., 1999. The antecedents of buying firms' efforts to improve suppliers. Journal of Management, 17 (2), 205-224.

Krause, D.R. \& Ellram, L.M., 1997. Success factors in supplier development. International Journal of Physical Distribution \& Logistics Management, 27 (1), 39-52.

Krause, D.R., Handfield, R.B. \& Scannell, T.V., 1998. An empirical investigation of supplier development: Reactive and strategic processes. Journal of Operations Management, 17 (1), 39-58.

Krause, D.R., Handfield, R.B. \& Tyler, B.B., 2007. The relationships between supplier development, commitment, social capital accumulation and 
performance improvement. Journal of Operations Management, 25 (2), 528545.

Leisinger, K.M., 2005. The corporate social responsibility of the pharmaceutical industry: Idealism without illusion and realism without resignation. Business Ethics Quarterly, 15 (4), 577-594.

Linton, J.D., Klassen, R. \& Jayaraman, V., 2007. Sustainable supply chains: An introduction. Journal of Operations Management, 25 (6), 1075-1082.

Locke, R., 2012. Promoting labor rights in a global economy, New York:Cambridge University Press.

Mahapatra, S.K., Das, A. \& Narasimhan, R., 2012. A contingent theory of supplier management initiatives: Effects of competitive intensity and product life cycle. Journal of Operations Management, 30 (5), 406-422.

Marshall, D., Mccarthy, L., Heavey, C. \& Mcgrath, P., 2015. Environmental and social supply chain management sustainability practices: Construct development and measurement. Production Planning \& Control, 26 (8), 673690.

Matten, D. \& Moon, J., 2008. 'Implicit' and 'explicit' CSR: A conceptual framework for a comparative understanding of corporate social responsibility. Academy of Management Review, 33 (2), 404-424.

Mcivor, R., 2009. How the transaction cost and resource-based theories of the firm inform outsourcing evaluation. Journal of Operations Management, 27 (1), 45-63.

Meyer, J.W. \& Rowan, B., 1977. Institutionalized organizations: Formal structure as myth and ceremony. American Journal of Sociology, 83 (2), 340-363. 
Miles, M.B. \& Huberman, A.M., 1994. Qualitative data analysis: An expanded source book $2^{\text {nd }}$ ed. Thousand Oaks: SAGE Publications.

Mills, A.J., Dureops, G. \& Wiebe, E. 2010. Encyclopedia of case study research, Los Angeles: SAGE Publications.

Modi, S.B. \& Mabert, V.A., 2007. Supplier development: Improving supplier performance through knowledge transfer. Journal of Operations Management, $25(1), 42-64$.

Oehmen, J., De Nardo, M., Schönsleben, P. \& Boutellier, R., 2010. Supplier code of conduct-- state-of-the-art and customisation in the electronics industry. Production Planning \& Control, 21 (7), 664-679.

Parmigiani, A., Klassen, R.B. \& Russo, M.V., 2011. Efficiency meets accountability: Performance implications of supply chain configuration, control, and capabilities. Journal of Operations Management, 29 (3), 212-223.

Pawar, K. \& Rogers, H., 2014. Mobilising knowledge across organisational boundaries: Addressing human issues in the telecommunications industry. Production Planning \& Control, 24 (7), 549-551.

Prahinski, C. \& Benton, W.C., 2004. Supplier evaluations: Communication strategies to improve supplier performance Journal of Operations Management, 22 (1), $39-62$.

Rogers, K.W., Purdy, L., Safayeni, F. \& Duimering, P.R., 2007. A supplier development program: Rational process or institutional image construction? Journal of Operations Management, 25 (2), 556-572.

Rossetti, C.L., Handfield, R. \& Dooley, K.J., 2011. Forces, trends, and decisions in pharmaceutical supply chain management. International Journal of Physical Distribution \& Logistics Management, 41 (6), 601-622. 
Salton, R. \& Jones, S., 2015. The corporate social responsibility reports of global pharmaceutical firms. British Journal of Healthcare Management, 21 (1), 2125.

Sanchez-Rodriguez, C., Hemsworth, D. \& Martinez-Lorente, A.R., 2005. The effect of supplier development initiatives on purchasing performance: A structural model. Supply Chain Management: An International Journal, 10 (4), 289-301.

Schneider, J.L., Wilson, A. \& Rosenbeck, J.M., 2010. Pharmaceutical companies and sustainability: An analysis of corporate reporting. Benchmarking: An international journal, 17 (3), 421-434.

Smith, A.D., 2008. Corporate social responsibility practices in the pharmaceutical industry. Business Strategy Series, 9 (6), 306-315.

Ulbrich, S., Troitzsch, H., Van Den Anker, F., Pluss, A. \& Huber, C., 2011. How teams in networked organisations develop collaborative capability: Process, cricical incidents and success factors. Production Planning \& Control 22 (5/6), 488-500.

Veleva, V., Hart, M., Greiner, T. \& Crumbley, C., 2003. Indicators for measuring environmental sustainability: A case study of the pharmaceutical industry. Benchmarking: An international journal, 10 (2), 107-119.

Voss, C., Tsikriktsis, N. \& Frohlich, M., 2002. Case research in operations management. International Journal of Operations \& Production Management, $22(2), 195-219$

Wagner, S.M., 2010. Indirect and direct supplier development: Performance implications of individuals and combined effects. IEEE Transactions On Engineering Management, 57 (4), 536-545. 
Wagner, S.M., 2011. Supplier development and the relationship life cycle. International Journal Production Economics, 129 (2), 277-283.

Wild, N. \& Zhou, L., 2011. Ethical procurement strategies for international aid nongovernment organisations. Supply Chain Management: An International Journal, 16 (2), 110-127.

Yin, R.K., 2009. Case study research: Design and methods Thousand oaks, CA.: Sage Publications.

Zhang, M., Pawar, K.S., Shah, J. \& Mehta, P., 2013. Evaluating outsourcing partners'capability: A case study from the pharmaceutical supply chain. Journal of Manufacturing Technology Management, 24 (8), 1080-1101. 


\section{Appendix 1. Semi-structured interview protocol}

1. What is the role of the sourcing department in the company?

2. What does the company source from external suppliers?

3. What are the main criteria for selecting suppliers?

4. How do you ensure Safety, Health and Environment (SHE) compliance?

5. What is being done around the area of corporate social responsibility (CSR) and sourcing?

6. How does the PSCI benefit the company?

7. What are the key challenges for sourcing in China?

8. Are suppliers reliable? If not, what does the company do to mitigate risk of the clinical supply chain (CSC)?

9. What is the role of the Study Manager and Study Drug Coordinator in sourcing?

10. How many sites are active and cater to?

11. What are the standard operation procedures (SOPs) and infrastructure for managing CSC?

12. What supporting services do the studies need?

13. What kinds of problems have you faced because of poor supplier CSR performance?

14. What are the key challenges for managing the CSC?

15. How can you improve CSR performance with regard to the CSC?

16. What is the role of the Quality Assurance (QA) department in sourcing?

17. How much emphasis is placed on SHE?

18. How often are audits carried out?

19. Do you train partners' staff on SOPs?

20. What kinds of performance failures are most common with regard to QA?

21. What is a QA manager's role in improving CSR? 


\section{Appendix 2. Interview details}

Table A1. Interview details

\begin{tabular}{|l|l|l|}
\hline \multicolumn{2}{|c|}{ Interviewee } & Sessions (Date DD/MM) \\
\hline MPC & Senior Manager (Global Sourcing Team) & $3(02 / 06,15 / 06,12 / 07)$ \\
\cline { 2 - 3 } & Quality Assurance Management & $3(17 / 06,18 / 07,05 / 08)$ \\
\cline { 2 - 3 } & Supply Chain Manager & $2(22 / 06,19 / 06)$ \\
\cline { 2 - 3 } & Study Drug R\&D Specialist & $2(21 / 07,22 / 07)$ \\
\cline { 2 - 3 } & Medical Director & $2(11 / 08,19 / 08)$ \\
\cline { 2 - 3 } & Regulatory Affairs Specialist & $1(21 / 07)$ \\
\cline { 2 - 3 } & Assistant Medical Director & $1(28 / 07)$ \\
\cline { 2 - 3 } & Clinical Research Associate & $1(10 / 07)$ \\
\cline { 2 - 3 } & Clinical Study Director & $1(12 / 08)$ \\
\cline { 2 - 3 } & Regulatory Affairs Specialist & $1(18 / 08)$ \\
\hline \multirow{5}{*}{ Supplier } & General Manager & $2(20 / 07,22 / 07)$ \\
\cline { 2 - 3 } & Associate Project Manager & $2(20 / 07,22 / 07)$ \\
\cline { 2 - 3 } & Key Account Manager & $1(18 / 07)$ \\
\cline { 2 - 3 } & Director & $1(19 / 07)$ \\
\hline
\end{tabular}


Appendix 3. Clinical supply chain

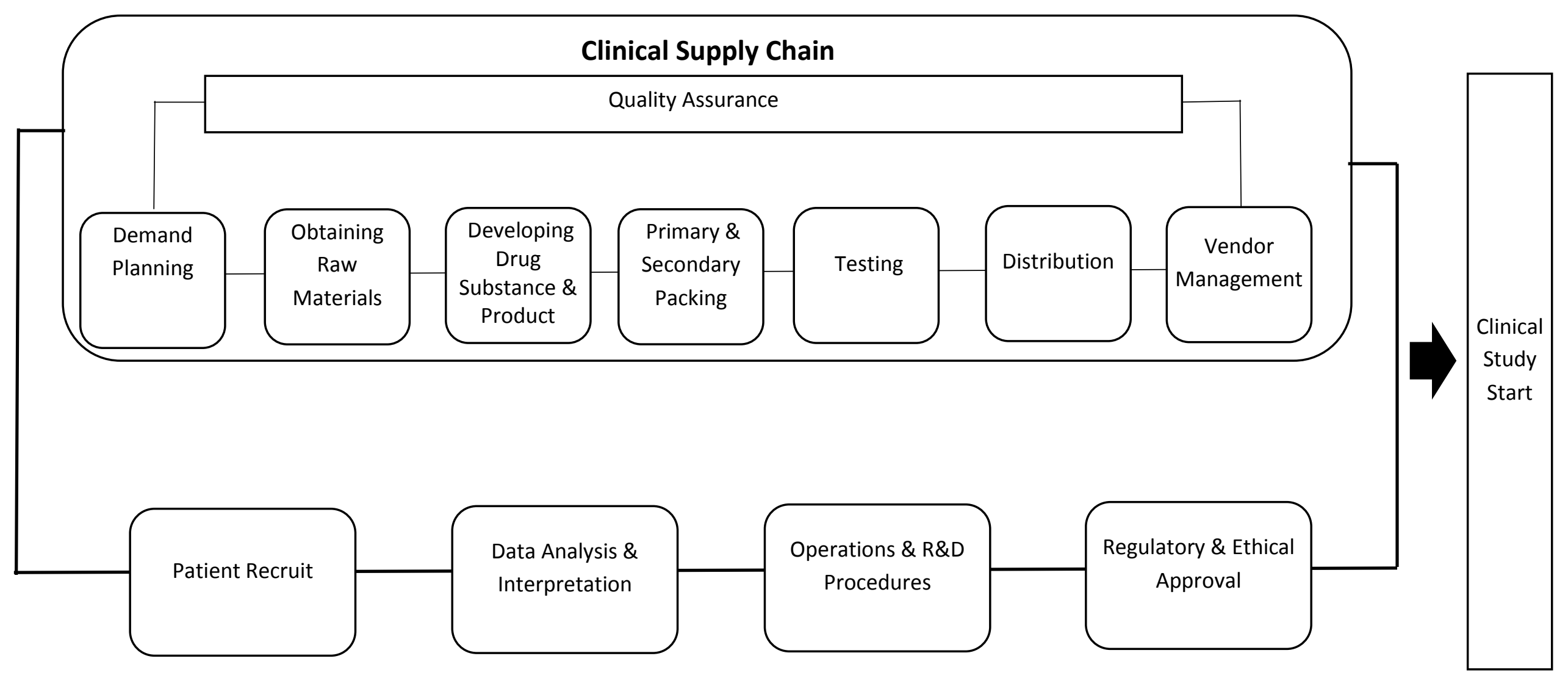

Source: Company document

Figure A1. Clinical supply chain 